\title{
On the electrification of gases by ignited bodies
}

\section{J. Elster \& H. Geitel}

To cite this article: J. Elster \& H. Geitel (1887) On the electrification of gases by ignited bodies, Philosophical Magazine Series 5, 24:147, 224-224, DOI: $10.1080 / 14786448708628085$

To link to this article: http://dx.doi.org/10.1080/14786448708628085

$$
\text { 册 Published online: } 29 \text { Apr } 2009 .
$$

Submit your article to this journal

Џ Article views: 2

Q View related articles $\sqsubset$ 
the use of a corrected lens, to avoid the absorption of flint-glass in the achromatic combination.

More or less absorption when glass is used is unavoidable; and this, with the variation of the focal plane of the lens for light of different wave-lengths, constitutes the most serious defects of the apparatus-defects which are avoided in the Rowland instrument. However, compensating advantages are not wanting. The Rowland apparatus integrates all impressions received at the slit. The ordinary comparison-prism cannot be used with it, and the lower orders of spectra are too narrow to admit of convenient division at the camera ; in fact, the spectra begin at nothing at the slit, and spread in a widening band as we move toward the higher orders.

The new instrument possesses the advantages of the analyzingspectroscope. The spectrum can be made wide or narrow, or divided at the slit. A preliminary trial has given the following results :- A flat grating of 14,000 lines to the inch and a ruled surface $2 \times 1 \frac{1}{2}$ inches was employed, with a lens of 37 -feet focus. The latter was placed close to the grating, and its spectrum observed near the slit. In the second spectrum $b_{1}$ and $b_{2}$ were fully an inch apart as projected on a sereen, and $D_{1}$ and $D_{2}$ had a separation of 13 to 14 millim.

The excellence of the definition is shown by the fact that, with an ordinary reading-glass of 6 -inch focus, $E$ was seen double, and fourteen lines were counted between $D_{1}$ and $D_{2}$. With this form of apparatus the amount of dispersion can be varied at pleasure by simply altering the relative distances of slit and camera from the grating, but in such a way that slit and camera shall occupy conjugate foci of the lens.-Silliman's American Journal, July 1887.

\section{ON THE ELECTRIFICATION OF GASES BY IGNITED BODIES.} BY J. ELSTER AND H, GEITEL.

The results of this investigation may be summed up as follows :-

(1) The phenomenon that insulated conductors near an ignited body are electrically charged holds also for gases, which bave been freed from dust by filtration through glycerine wadding.

(2) This holds also even when the rarefaction is raised to the extreme limits of a Crookes's tube.

(3) The electrification is positive for red heat; and all temperatures beyond in all gases as yet examined, with the exception of hydrogen, which at a high temperature has the opposite behaviour.

(4) For air and carbonic acid the maximum of electrification is at a yellow heat.

(5) The layer of gas which surrounds an incandescent body shows a different deportment as respects positive and negative electricity. That electricity whose sign is opposite that developed in the gas by ignition is most rapidly discharged.-Wiedemann's Annalen, No. 5, 1887. 